\title{
Micrometastases: marker of metastatic potential or evidence of residual disease?
}

\author{
G C O’Sullivan, J K Collins, J Kelly, J Morgan, M Madden, F Shanahan
}

\begin{abstract}
Background-Micrometastases within bone marrow have been shown to indicate a poor prognosis in patients with epithelial tumours. However, the degree to which micrometastases represent true residual disease or cell shedding and metastatic potential, is unclear.

Aim-To explore whether micrometastases represent residual disease, bone marrow taken from carefully staged patients before and after (>6 months) 'curative' resection of a primary gastrointestinal cancer was studied prospectively.

Patients/Methods-Seventy two consecutive patients were studied; the only exclusions were patients with known overt metastatic disease at the time of surgery. Micrometastatic cells were quantified per $10^{5}$ marrow cells by flow cytometry after staining for contaminant cytokeratin-18 positive cells.
\end{abstract}

Results-Micrometastases were detected preoperatively in $22 \%(16 / 72)$ of all patients, comprising $11(23 \%)$ of 48 with colorectal cancer, five (33\%) of 15 with gastric adenocarcinoma and none $(0 \%)$ of nine with oesophageal squamous cancer. Although fewer metastatic cells were detected in postoperative bone marrow, and clearance of marrow deposits was evident in most patients, the persistence of micrometastases in five of 16 patients after resection, without evidence of tumour recurrence, indicates a subset with true residual disease. Detection of micrometastases postoperatively (persistent or newly developed) was significantly associated with development of overt metastases during the subsequent 12-18 months of follow up (nine of 19 patients) when compared with patients testing negative for micrometastases (eight of $53 ; \mathrm{p}<0.01$ ). Conclusions-Preoperative detection of micrometastases may reflect either transient shedding of cells, metastatic potential or residual disease, but postoperative micrometastases indicate minimal residual disease. Identification of these patients is important because they may benefit from adjuvant therapy.

(Gut 1997; 40: 512-515)

Surgery and Medicine, National University of Ireland, Cork, Ireland

Correspondence to: Professor F Shanahan, Department of Medicine Cork University Hospital, Cork, Ireland.

Accepted for publication 28 November 1996

Keywords: metastases, cancer, residual disease, flow cytometry.

Detection of bone marrow micrometastases using immunocytochemical methods has been shown to be a predictor of poor prognosis in patients with breast, ${ }^{12}$ lung, ${ }^{34}$ and colorectal cancer. ${ }^{5}$ We recently validated flow cytometry as a more objective method of demonstrating and quantifying micrometastatic cells and have shown that bone marrow micrometastases are present in approximately one quarter of patients undergoing 'curative' resection of gastrointestinal adenocarcinomas. ${ }^{6}$ Whether micrometastases reflect cell shedding from the primary tumour, the metastatic potential of the primary tumour or represent residual disease is not clear. The question is of therapeutic importance because patients with true residual disease may benefit from adjuvant therapy. ${ }^{7}$ Dormant micrometastatic foci of residual disease in various organs must exist because it is well recognised that patients with a prior resection of a primary cancer can present late with distant metastatic disease, in the absence of a local recurrence. ${ }^{9}$ To explore whether microdeposits of metastatic cells in the bone marrow are foci of residual disease or simply reflect transitory cells shed from bulky tumours, we undertook a prospective study of bone marrow taken from patients before and after (six to 12 months) resection of a primary gastrointestinal carcinoma.

\section{Methods}

Seventy two consecutive patients undergoing potentially curative surgical resection of a gastrointestinal malignancy were included in the study. Patients with known metastases demonstrable by conventional or non-surgical means were excluded; there were no other exclusions. Diagnostic and clinical investigations for staging of all patients comprised standards of care in accordance with guidelines of the human ethics committee for clinical research. Informed consent for surgery and bone marrow aspiration was obtained in all cases. Control marrow was obtained from 63 patients (with no evidence of malignant epithelial disease) undergoing bone marrow aspiration for haematological indications. All control marrow samples were negative for micrometastatic cells with the exception of one 58 year old woman with rheumatoid arthritis, in whom there has been no clinical evidence of malignant disease.
CLINICAL STAGING

Clinical staging of patients diagnosed with colorectal carcinoma included chest radiography, ultrasonography, and an abdominal computed tomography (CT) scan. A full laparotomy with bi-manual palpation of the liver and exploration of the peritoneal cavity was 
Bone marrow micrometastases before and after 'curative' resection of a primary gastrointestinal tumour

\begin{tabular}{|c|c|c|c|c|c|}
\hline \multicolumn{4}{|c|}{ Micrometastases } & \multirow{2}{*}{\multicolumn{2}{|c|}{$\begin{array}{l}\text { Development of overt } \\
\text { metastases within } \\
\text { subsequent year of follow up }\end{array}$}} \\
\hline \multirow{2}{*}{$\begin{array}{l}\text { Preoperative } \\
\text { Positive }\end{array}$} & \multirow{2}{*}{$\begin{array}{l}\text { Postoperative } \\
\text { Positive }\end{array}$} & \multicolumn{2}{|l|}{$n$} & & \\
\hline & & 5 & 2 colonic & $4 / 5$ & 1 colonic \\
\hline Positive & Negative & 11 & $\begin{array}{l}9 \text { colonic } \\
2 \text { gastric }\end{array}$ & $0 / 11$ & \\
\hline Negative & Positive & 14 & $\begin{array}{l}11 \text { colonic } \\
2 \text { gastric } \\
1 \text { oesophageal }\end{array}$ & $5 / 14$ & $\begin{array}{l}2 \text { colonic } \\
2 \text { gastric }\end{array}$ \\
\hline Negative & Negative & 42 & $\begin{array}{l}26 \text { colonic } \\
8 \text { gastric } \\
8 \text { oesophageal }\end{array}$ & $8 / 42$ & $\begin{array}{l}4 \text { colonic } \\
1 \text { gastric } \\
3 \text { oesophageal }\end{array}$ \\
\hline
\end{tabular}

performed and, when appropriate, a radical resection of the primary tumour including mesentery of bowel was completed. For patients with gastric cancer, routine staging investigations included an abdominal CT scan and ultrasound followed by laparoscopy. If no metastases were evident on laparoscopy, a full laparotomy with radical resection was performed. Patients with oesophageal and oesophagogastric junction tumours were staged with a CT scan of the chest and abdomen and abdominal ultrasound followed by laparoscopy and bronchoscopy preoperatively. The oesophagus was surgically explored through the chest and mobilised. The chest was then closed and an abdominal exploration was performed in which the liver was bi-manually palpated. The oesophagus was excised and reconstruction performed by anastomosis of cervical oesophagus to transposed stomach or colon graft.

Patients were re-examined six to 12 months postoperatively by repeat bilateral iliac crest bone marrow aspiration and by re-staging which included clinical, radiographic (chest CT scan, ultrasound), and endoscopic evaluation and measurement of tumour markers

Postoperative

\begin{tabular}{|c|c|c|c|c|c|}
\hline & Posit & tive & $\mathrm{Neg}$ & jative & \\
\hline & $\mathrm{n}=$ & & & $=11$ & \\
\hline Positive & Gastric (3) & $\begin{array}{l}\text { T3NO } \\
\text { T2N1 } \\
\text { T2NI }\end{array}$ & Gastric (2) & $\begin{array}{l}\text { T2N1 } \\
\text { T3N0 }\end{array}$ & \\
\hline & Colonic (2) & $\begin{array}{l}\text { C T3N1 } \\
\text { C T3N1 }\end{array}$ & Colonic (9) & $\begin{array}{l}\text { A T2 } \\
\text { B T2 } \\
\text { B T3 } \\
\text { C T2N1 }\end{array}$ & $\begin{array}{l}(n=2) \\
(n=5)\end{array}$ \\
\hline arive & $n=$ & 14 & & $=42$ & \\
\hline & Gastric (2) & $\begin{array}{l}\text { T2N1 } \\
\text { T2N1 }\end{array}$ & Gastric (8) & $\begin{array}{l}\text { T2N0 } \\
\text { T2N1 (r } \\
\text { T3N1 (r } \\
\text { T3N3 ( }\end{array}$ & $\begin{array}{l}(n=2) \\
(n=3) \\
(n=2)\end{array}$ \\
\hline Negative & Oesophageal (1 & 1) $\mathrm{T} 2 \mathrm{~N} 1$ & Oesophageal & $\begin{array}{l}\text { 8) T2N0 ( } \\
\text { T3N0 } \\
\text { T1N1 ( } \\
\text { T2N1 ( }\end{array}$ & $\begin{array}{l}(n=3) \\
(n=2) \\
(n=2)\end{array}$ \\
\hline & Colonic (11) & $\begin{array}{l}\text { A T1 } \\
\text { A T2 } \\
\text { В T3 } \quad(n=6) \\
\text { С T3N1 }(n=3)\end{array}$ & Colonic (26) & $\begin{array}{l}\text { A T1 } \\
\text { A T2 } \\
\text { B T2 } \\
\text { B T3 } \\
\text { С T3N1 }\end{array}$ & $\begin{array}{l}(n=2) \\
(n=5) \\
(n=14) \\
(n=4)\end{array}$ \\
\hline
\end{tabular}

Figure 1: Distribution of bone marrow micrometastases before and after surgery for tumour site and stage. (carcinoembryonic antigen (CEA) and carcinoma antigen (CA) 19-9). All patients were reviewed clinically every three to six months thereafter; no patients were lost to follow up.

\section{EXAMINATION OF BONE MARROW}

Marrow was taken from both iliac crests, using aseptic technique, under general anaesthesia preoperatively - that is, before bowel resection or manipulation, and under local anaesthesia postoperatively. An incision over the iliac crest was used to enable the marrow aspirate to be taken without contamination by skin epithelia. The unfractionated marrow was fixed by addition dropwise with gentle shaking into $70 \%$ ethanol and was stored at $-20^{\circ} \mathrm{C}$ until use. The flow cytometry technique has been described and validated elsewhere. ${ }^{6}$ The flow cytometrist was unaware of the patients' diagnosis at the time of testing. Bone marrow samples were washed three times with phosphate buffered saline (PBS) at $4^{\circ} \mathrm{C}$ and stained with fluorescein isothiocyanate (FITC) conjugated monoclonal antibody directed against cytokeratin-18 (Sigma, Poole, Dorset, UK). The antibody was diluted 1 in 20 in PBS and $10 \mu \mathrm{l}$ of this stock antibody was added to 100 $\mu l$ sample. After washing in PBS again, staining for DNA content was completed with propidium iodide containing RNAse. The cells were then analysed ( $10^{5}$ events) using a cell cycle analysis program on an Epics Coulter Elite flow cytometer. Only double staining cells were counted as positive, thereby excluding non-specific staining or spuriously stained debris. Positive (HT29 and OC1 cells) and negative (normal bone marrow) controls were included in all analyses. ${ }^{6}$ Threshold and background fluorescence were controlled for using an irrelevant FITC conjugated monoclonal antibody of the same species and isotype as anti-cytokeratin-18.

Micrometastatic cells were detected by light microscopy in some cases after FicollHypaque density centrifugation ${ }^{11}$ and were stained with cytokeratin-18 using the alkaline phosphatase-anti-alkaline phosphatase (APAAP) technique. ${ }^{511}$

STATISTICAL ANALYSIS

Patients with and without micrometastases detected postoperatively were compared in terms of development of overt metastases within a subsequent year of follow up. Differences between patient groups were examined using $\chi^{2}$ analysis with Yates's correction.

\section{Results}

The Table shows the prevalence of bone marrow micrometastases before and after (six to 12 months) resection of the primary gastrointestinal malignancy, with the rate of development of overt metastatic disease during the subsequent year of follow up. The presence of micrometastases before or after surgery did not correlate with either tumour site or stage (Fig 1). Sixteen of the 72 consecutive patients 


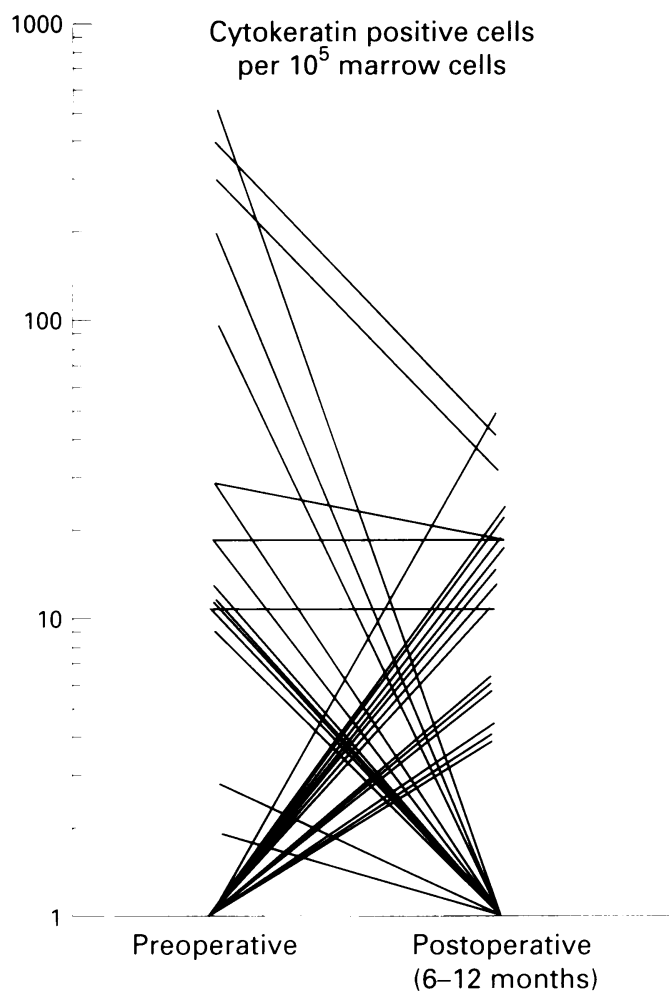

Figure 2: Quantitation of bone marrow micrometastatic cells before and after resection of the primary tumour. The mean (SEM) micrometastatic cell count (per $10^{\circ}$ marrow" cells) in those patients testing positive preoperatively was 90 (30) $(n=16)$ and in those testing positive postoperatively. was 42 (10) $(n=19)$.

eligible for study had bone marrow micrometastases before surgery. Five of these were still positive for micrometastases six to 12 months after resection of the primary tumour, at a time when there was no evidence of local recurrence. That this represents true residual disease in this subset of patients is supported by the subsequent development of overt metastases in all but one during the subsequent year of follow up (one brain, one liver, one liver and bone metastases, one serosal).

By contrast, 11 of the 16 patients who had tested positive before surgery were negative afterwards. That this represents clearance of shed or metastatic cells is supported by the absence of overt metastases during the subsequent year of follow up. In all cases tumour marker values (serum CA 19-9 and CEA) remained normal. Indirect evidence for clearance of metastatic cells by the host is also shown by the strong trend toward lower metastatic cell counts in the postoperative period (Fig 2). Direct visualisation of such cells on immunostained smears of bone marrow cells indicated that the microdeposits exist either as isolated single viable cells or as small clumps (Fig 3). The difference in the rate of development of overt metastases between those patients who had persistent micrometastases before and after surgery and those who had clearance of micrometastases postoperatively was statistically significant $(4 / 5 v$ $0 / 11 ; \mathrm{p}<0 \cdot 01)$.

The development of micrometastases in patients who had tested negative before surgery was also observed in 14 patients (14/56). Five of these have since developed evidence of overt metastatic disease (one lung, two brain, one bone, and one liver) and one additional patient has developed persistently abnormal increases in CEA and CA 19-9 values without evident tumour recurrence yet.

As expected, the bone marrow sampling process has limited sensitivity; micrometastases were not detected either before or after surgery in 42 of the 72 patients. Eight of these patients (three oesophageal squamous cancer, one gastric and four colonic) developed overt metastatic disease during the subsequent year of follow up. The distribution of these metastases was liver (three patients), liver and bone (one), lung (one) brain (two), and lung and bone (one). The clinical relevance of detecting micrometastases in the marrow postoperatively is indicated by significant differences in the rate of development of overt metastases in the subsequent year of follow up. Thus, overt metastases developed in a total of nine of 19 patients testing positive for marrow micrometastases after surgery compared with eight of 53 testing negative after surgery $(p<0 \cdot 01)$.

\section{Discussion}

It has been shown by others that bone marrow micrometastases are a marker of poor prognosis in patients with epithelial tumours, including breast, lung and colorectal carcinoma. ${ }^{15}$ However, the mechanism by which the micrometastatic process confers a poor outcome is uncertain. There has been no conclusive evidence that microdeposits represent residual disease. It is unclear whether the metastatic cells per se have biological significance, viability and longevity or whether their presence is merely a reflection of the biological behaviour of the primary tumour. These questions are important because if micrometastases reflect true residual disease, they could be used to identify an important subgroup of patients who might benefit from adjuvant therapy after surgery. ${ }^{7} 8$ Implicit in this would be a requirement to consider

Figure 3: Cytokeratin positive cells within bone marrow as single isolated cells and as microcolonies. 
revising current staging procedures to incorporate an assessment for microdeposits.

Our results clearly demonstrate a distinct subset of patients (approximately $10 \%$ of the total) who fail to clear micrometastatic cells after 'curative' surgical resection of a primary gastrointestinal malignancy. These patients have persistent occult deposits of cancer cells within the bone marrow that are demonstrable at a time when there is no primary tumour or local recurrence capable of shedding cells. Thus, these patients have true residual disease.

The presence of micrometastases in patients after surgery, irrespective of the preoperative bone marrow status, was associated with a poor short term outcome. Detection of micrometastases postoperatively antedated and was significantly associated with the development of overt metastases when compared with those patients who tested negative for micrometastases after surgery (9/19 $v 8 / 53 ; \mathrm{p}<0.01)$. Thus, postoperative bone marrow status may be a useful adjunct to current staging protocols.

The bone marrow is generally viewed as an optimal site to look for micrometastases because it is a rich cellular site with a large blood supply and because cytokeratin positive epithelial deposits are easily identifiable in mesenchymal tissues. ${ }^{12}$ However, it seems likely that other tissues such as liver and lung also harbour dormant microdeposits of residual disease, but these epithelial tissues require alternative techniques for demonstrating micrometastases. The presence of dormant micrometastatic foci of residual disease in organs such as the liver or lung presumably accounts for the occasional late presentation of distant metastatic disease without local recurrence in patients who have had a prior resection of a primary gastrointestinal cancer. ${ }^{9}$

Alternatively, occult deposits of metastatic cells within the marrow may have additional biological significance beyond serving as an indicator of the metastatic process and distant residual disease within other organs. Mobilisation of tumour cells from bone marrow into the periphery has recently been demonstrated in patients with solid tumours. ${ }^{13} 14$ Thus, the bone marrow might serve as a repository of dormant metastatic cells from which other sites could be seeded.

Although the presence of residual disease is confirmed by the finding of micrometastases six to 12 months after surgery, our results also show that when micrometastases are detected preoperatively, some do not persist and may represent transient shed cells that the host can clear. Quantification using flow cytometry revealed that fewer metastatic cells were evident in postoperative marrows and clearance was evident in most cases. However, it is noteworthy that the design of our study ensured that any shedding of cells was spontaneous and not due to mobilisation of the primary tumour at surgery, as described by others. ${ }^{15}$

In conclusion, preoperative detection of micrometastases may reflect either transient shedding of cells, metastatic potential or residual disease, but postoperative micrometastases are likely to indicate minimal residual disease, at which adjuvant therapeutic strategies should be directed. The need for improved staging of all forms of gastrointestinal cancer is clearly desirable as many of these cancers are understaged even after surgical excision. ${ }^{16}$ The results challenge current staging protocols and show that postoperative bone marrow examination can reveal detectable minimal residual disease in patients after 'curative' resection of a gastrointestinal malignancy.

This work was supported in part by the Health Research Board of Ireland and the Cancer Research Appeal Mercy Hospital (CRAM). The technical assistance of Bernie Crowley and Dr Fiona O'Brien is gratefully acknowledged.

This work has been presented in part at the DDW/AGA
Then This work has been presented in part at the DDW/AGA
annual meeting, San Francisco, May 1996, and appears in abstract form in Gastroenterology 1996; 110: A571

1 Mansi JL, Berger U, Easton D, McDonnell T, Redding WH, Gazet JC, et al. Micrometastases in bone marrow in patients with primary breast cancer: evaluation as an early predictor of bone metastases. BMF 1987; 295: 1093-6.

2 Cote RJ, Rosen PP, Lesser ML, Old LJ, Osborne MP. Prediction of early relapse in patients with operable breast Prediction of early relapse in patients with operable breast metastases. $\mathcal{f}$ Clin Oncol 1991; 9: 1749-56.

3 Cote RJ, Beattie EJ, Chaiwun B, Shi S-R, Harvey J, Chen S-C et al. Detection of occult bone marrow micrometastases in patients with operable lung carcinoma. Ann Surg 1995; 222: 415-25.

4 Pantel K, Izbicki J, Passlick B, Angstwurm M, Haüssinger K, Thetter $\mathrm{O}$, et al. Frequency and prognostic significance of isolated turmour cells in bone marrow of patients with non-small-cell lung cancer without overt metastases. Lancet 1996; 347: 649-53.

5 Lindemann F, Schlimok G, Dirschedl P, Witte J, Riethmüller G. Prognostic significance of micrometastatic tumour cells in bone marrow of colorectal cancer patients. tumour cells in bone marr $1992 ; 340: 685-9$.

6 O'Sullivan GC, Collins JK, O'Brien F, Crowley B, Murphy K, Lee G, Shanahan F. Micrometastases in bone marrow of patients undergoing "curative" surgery for gastrointestinal cancer. Gastroenterology 1995; 109: 1535-40.

7 Nossal GJV. Minimal residual disease as the target for immunotherapy of cancer. Lancet 1994; 343: 1172-4.

8 Sinicrope FA, Sugarman SM. Role of adjuvant therapy in surgically resected colorectal carcinoma. Gastroenterolog 1995; 109: 984-93.

9 Folkman J. Angiogenesis in cancer, vascular, rheumatoid and other disease. Nat Med 1995; 1: 27-31.

10 Boyum A. Separation of leukocytes from blood and bone marrrow. Scand $\mathcal{f}$ Clin Lab Invest 1968; 21: 31-50.

11 Cordell JL, Falini B, Erber WN, Gosh AK, Abdulaziz Z MacDonald $S$, et al. Immunoenzymatic labelling of monoclonal antibodies using immune complexes of alkaline phosphatase and monoclonal antialkaline phosphatase (APAAP complexes). f Histochem Cytochem 1984; 32: $219-29$.

12 Schlimok G, Riethmüller G. Detection, characterization and tumorigenicity of disseminated tumor cells in human bone marrow. Semin Cancer Biol 1990; 1: 207-15.

13 Brugger W, Bross KJ, Glatt M, Weber F, Mertelsmann R, Kanz L. Mobilisation of tumor cells and hemapoietic progenitor cells into peripheral blood of patients with solid tumors. Blood 1994; 83: 636-40.

14 Shpall EJ, Jones RB. Release of tumor cells from bone marrow. Blood 1994; 83: 623-5.

15 Eschwege P, Dumas F, Blanchet P, Le Marie V, Benoit G, Jardin A, et al. Haematogenous dissemination of prostatic epithelial cells during radical prostatectomy. Lancet 1995; 346: 1528-30.

16 Rubio CA, Emas S, Nylander G. A critical reappraisal of Dukes' classification. Surg Gynecol Obstet 1977; 145: $682-4$ 